\title{
VERKLARING VAN DE IN DE DOCUMENTEN VOORKOMENDE VREEMDE WOORDEN EN UITDRUKKINGEN. ${ }^{1}$ )
}

A.

aguilhout, welriekend hout van den aloë-boom: 212, 463, 498, 552. alphandigo, Portugeesch alfande$g a$, tolhuis, kantoor der in- en uitvoerrechten: 132.

amien, gemachtigde, intendant: 120, 201, 207.

ammarouw, zie omrah. anachoda, zie nachoda. armane, hof, regeering van Madura in Voor-Indië: 378-380. aroe, sultan: 137, 138, 290, 291, $372,373,375$.

arsie of arsir, verzoekschrift: $\mathbf{4 4 6}$, 517.

atap, dakbedekking van gedroogde palmbladen: 166, 167 .

atemaet-al-doulet of atimad-dauleth, Perzisch ehtemaed-uddowleh, titel van den rijksbestuurder van Perzië: 94, 95, 97, $98,124,455,456,470$.

auweldaar, zie havildar.

ayen, suffix bij een persoonsnaam, aanduidende dat de drager een Brahmaan is: $147,377$.

B.

badam of bodom, letterlijk een amandel, overdrachtelijk een kleinigheid, een peulschil: 295 . bahadur of bhadur, suffix bij vorstennamen, met de beteekenis held: 299, 301, 304, 315, $318,387,395,446,518,519$. balagat, inheemsch roeivaartuig in Voor-Indië: 417.

balai of balai-desa, „raadhuis”: 241.

balleeuw, zie balai.

bandar, haven, ,zeekoopstad": 73, 136, 305.

bandara, zie dato bandara.

banksaal of bangasal, kantoor der in- en uitvoerrechten, entrepot. Zie Corpus III, blz. 608: 55, 147, 342, 508.

bara-antara, Bataksche titel met de beteekenis beschermer of „voorspreker”: 143.

barquiers, schuitenvoerders: 141. beg, suffix bij persoonsnamen met de beteekenis heer of chef. De vrouwelijke vorm is begum: passim.

begler begi, Perzische titel voor gouverneurs van een provincie, letterlijk beteekenende heer der heeren: 90, 106, 107, 522.

Benjaan, Hindoesch koopman: 110, 494, 504, 522, 561.

benjuin of benjoin, benzoëhars: $19-21,73,74,85,212,463,498$. berkelang, zie oya bercquelang.

1) De cijfers verwijzen naar de bladzijden, waar het woord voorkomt; de vetgedrukte cijfers naar die bladzijden, waar men een korte omschrijving en soms ook een literatuurverwijzing aantreft.

Van woorden, die herhaaldelijk voorkomen, zijn slechts enkele plaatsen opgegeven. 
bobatos, boepatih's, regenten of rijksgrooten: $165,181,182,312$, 546.

boyeers, ossendrijvers: 57 .

boys, draagossen: 381 .

boysdragt, ossendracht: 381 .

\section{C. (Zie ook $\mathbf{K})$.}

cabaram, zie kabaram.

cabessa, Portugeesch voor hoofd, aanduiding voor le kwaliteit: 17, 21, 74 .

cagie, zie kadi.

caluwang, Siameesche ambtenaarstitel: 393.

candil, last van circa 480 pond, verdeeld in 14 parra's: 125, 126, 132, 364, 415 .

cannecappel, inheemsch klerk of boekhouder: 141, 206, 379.

capitan-laoet, inheemsche titel met de letterlijke beteekenis „hoofdman der zee”: 313.

cardamon, Maleisch kardamoenggoe, welriekende specerij, ,paradijskorrel": $212,462,498,552$. carga of carge, een baal zijde ter zwaarte van 36 man-i-shah of 216 K.G.: $5-7,117,118,153$, 209-211 etc ${ }^{\mathrm{n}}$.

carori, zie crori.

carre, Boegineesche beleefdheidstitel: 376.

carwary, ook geschreven charwari of karvary, ezelslast of ,beestedragt" van 216 K.G. Het woord kreeg ook de beteekenis: zijde van 2 de kwaliteit: 5, 451, 452, 457, 463.

casi, zie kadi.

castas, standen: 206 .

cattabarra, doorvoerrechten; éénmaal - hiervóór blz. $302-$ omschreven door "houttol": 298, 300, 302.

catti of catti-China, gewichtseenheid $\operatorname{van}^{1 / 100}$ pikoel of \pm 6 ons: $136,538$. caul, officieel geschrift, gunstbrief. Zie Hobson-Jobson in voce cowl: passim.

caymael, vorstentitel aan de kust van Malabaar, meest vertaald door vrijheer: 259-261, 512, 515.

caytchill, Moluksche titel voor leden van een sultansfamilie, prins: $185,214,236,237,310$, 313.

chan of khan, suffix bij persoonsnamen, oorspronkelijk met de beteekenis heer of prins, later algemeen gebruikt voor voorname Hindostani: passim.

chanesamaan, Hindostani khansama, titel voor een major-. domus, bij de Compagnie vertaald door "huysbesorger" of "generael rentmeester over 's conings domeynen": 402 , $408,409$.

chao-klang, Siameesche ambtenaarstitel. Het eerste lid, chao, is de algemeene aanduiding voor lieden van adellijke afstamming: 24, 393.

charwar of charwari, zie carwary. checkela, district: 292.

chitty, titel voor leden van de handelskaste: 380 .

chokidar, waker, opzichter: 301, 518.

cobang of coubang, Japansche gouden munt ter waarde van circa f 30: 473.

cobido, el: 415, 566 .

coeroeri, zie crori.

coetwael, Hindostani cotwal, hoofd der politie: 252 .

cojang of coyang, scheepslast van circa 30 pikoel: 82 .

cora-cora, gewapende prauw: 184.

costumados, Portugeesch, gebruikelijke tollen of rechten: 129 , $141,142$.

crain, zie karaeng. 
crommecan, zie kromakan.

crori, ontvanger der belastingen, tollenaar: 120, 226, 229, 299, $304,405,424,433$ etc $^{\mathrm{a}}$.

croutecan, Siameesch, vergadering, raad: 24 .

curcuma, gele verfstof van plantaardigen oorsprong: 86.

\section{D.}

daats, Chineesch-Maleisch datjin, unster of weegstok: 336, 532, 538.

dain of daëng, Boegineesche titel: 192, 367, 368, 376, 487.

dajang, vrouwelijke hofbediende, „hofjuffer”: 548.

daroga, Voorindische titel, gouverneur, ook hoofd van de munt: 407.

dato bandhara, titel van een voornaam hoofd in de Menangkabausche landen. Zoowel bandhara als dato, welk laatste woord oorspronkelijk grootvader beteekent, zijn op zichzelf ook al ambtstitels. De datobandhara is zooveel als de 1e minister: 440, 445.

dayen, zie dajang.

desmiochi of desmioegi, tolambtenaar: 202.

dessay, Mahratti desai, districtshoofd: $\mathbf{5 6 7 .}$

destek, paspoort, vrijbrief: 261, 276, 292, 294, 295, 298, 300 etc $^{\mathrm{a}}$. digmittie of digmissie, invoerrechten: 142.

dinar, Perzische munt, $1 / 10.000$ toman: 6, 118, 455, 456 etc $^{\mathrm{a}}$.

diwan, zie duan.

djoeroe-toelis, schrijver of secretaris: 185.

djogoegoe, titel van een rijksbestuurder in de Molukken: 313. djoöe, Moluksche titel met de beteekenis heer: 214.

Djulfalijnen, bewoners van Djulfa, de Christen-Armenische voorstad van Ispahan: 112.

duan, in Hindostan hoofd der financiën, in Perzië ,raad des konings": $23,96,101,105,124$, 141, 202, 206 etc $^{\mathrm{a}}$.

duan-begi, geestelijke opperrechter in Perzië, ,heer der justitie": 503, 559.

\section{E.}

Emir el omrah of Amir ul umra, letterlijk heer der heeren, titel voor een legerbevelhebber: 396 .

\section{F.}

fanum, munt ter waarde van $1 / 12$ pagode: 134, 142, 351-356, etc $^{\mathrm{a}}$. Men onderscheidde kleine fanums en gewone fanums, ook genoemd fanum-ragia of koningsfanums.

fausdar, ambtenaarstitel, gouverneur, hoofd der financiën, tollenaar: 120, 129, 201, 202, 204, 207, 252, 292 etc $^{\mathrm{a}}$.

feitoor, Portugeesch feitor, koopman, resident of ,legger": 229. Firingi of Franken, Perzische en Turksche naam voor Europeanen: 94, 95, 117.

firman of fermaan, uit naam des konings verleende gunstbrief „koninklijk mandaat”: passim. Frank, zie Firingi.

G.

gans, rijstmaat: 141 . garaem, belasting op granen: 418 . garioffel-nagelen, 1e kwaliteit kruidnagelen: 212, 463. geharpt, gezeefd; zie harp. geraym, zie garaem. goegoegoe, zie djogoegoe. goemoet, Maleisch gěmoetoe, de zwarte, harige vezels van den 
arèn-palm, waarvan o.a. touw gemaakt wordt: 168.

goeriep, ambtenaarstitel aan de kust van Malabaar: 177, 364.

goeserbanaan, ook geschreven goeserbaran, goserbant, etc $\mathrm{n}^{\mathrm{n}}$, verbastering van guzarban, titel van een tolambtenaar, omschreven als ,commissaris der veeren en overvaarten": $301,304$.

gomastos, Hindostani gomāshta, gemachtigde. Het wordt zoowel gebruikt voor een makelaar als voor den gemachtigde van een vorst of gouverneur. Het meest komt het voor als de benaming van een inheemsch agent der Europeesche Compagnieën: 301, 400, 401.

gonting of koenting, inheemsch zeilvaartuig: 443.

guastos, Portugeesch gastos, onkosten: 132.

\section{H.}

hadji, Mekka-ganger of pelgrim: 145, 319.

harp, schuinstaand fijn rooster om peper of andere specerijen te zeven of te ,harpen”: $336,532$.

hasbul-hockum, ,expresse ordre” of ,keizerlijk bevelschrift": 22, 115, 124, 221, 223, 294 etc $^{\mathrm{a}}$.

hasbul-ommer, hetzelfde als hasbul-hockum: 294, 299, 301, 319. hasia, zie hadji.

havildar, gouverneur van een havenstad, „landregent”: 56,57 , 140, 252.

hockiel, doubletvorm van wakil, zie aldaar.

hoedendragers, Europeanen: 145, 151, 221, 222, 299, 446.

hoekoem of oekoeng, volkshoofd, opperste kamponghoofd, in de Minahassa ook wel vertaald door rechter of richter: 162, 163, 165, 166, 313, 475. horri of horry, klein open vaartuigje: 145.

howay, zekere te betalen rechten in Perzië: 93.

I.

idanoi (Niasch) rivier: 38, 45. ieckoed, ,,passagiegelden”: 305. igmettie of igmissie, uitvoerrechten: $\mathbf{1 4 2 .}$

imam, voorganger in de moskee, ook titel voor Mohamedaansche hoofden of heerschers, b.v. de imam van Arabië: 220, 313, 438, 439.

ingabey, zie ngabehi.

inktkokers, naam voor kubusvormige blokjes tin van circa 2 pond: 539 .

\section{J.}

jagabey, zie ngabehi.

jagier of jagir, apanage, ambtelijk landbezit: 252.

jagierdar, apanagehouder: 226, 276, 292, 296, 299, 301, 304, 400, 405 etc $^{\mathrm{a}}$.

jang di pertoean, titel voor een vorst of rijksbestuurder in de Maleische landen: 445.

jemadar, ambtstitel met verschillende beteekenissen, als hoofd der politie, leenman, landvoogd: 276, 295, 296, 299, 304 etc $^{\mathrm{a}}$. jonkom, in- en uitvoerrechten: 204, 252.

juchten, ossenhuiden: 393, 394.

K. (zie ook C).

kaanko, kaankovi, enkele der vele verbasteringen van kānungo, d.i. een wetuitlegger, ook gebruikt als titel voor belastingambtenaren. Zie WILSON in voce: 202, 204. kaatbhara, zie cattabarra. 
kabaram, lasten, te betalen bij vervoer van goederen langs de wegen: $\mathbf{4 1 6}$.

kadi, titel voor een ambtenaar, rechter, of priester: 8, 226, 227. Het woord werd in Indië uitgesproken als kaadsjie, vandaar dat men ook geschreven vindt: casi, chasie en cagie.

kalangs, nomaden op Java: 246.

kalantar, letterlijk meerdere, titel voor een burgemeester in Perzië: 110.

kandijl, zie candil.

karaëng, vorstelijke titel op ZuidCelebes: 198, 367, 368, 373, $375,376$.

karavanserai, rustplaats voor karavanen: 179 .

karga, zie carga.

karrory, zie crori.

karvary, zie carwary.

kasy, zie kadi.

katib, Maleisch, schrijver: 220.

ketgoda-pessent, Perzisch kedkhoda passand, naam voor zijde (soms ook wol) van de allerbeste kwaliteit. Zie voor de beteekenis HoTz, Cunaeus, blz. 155, 156 noot: 210, 211, 463, 495, 497, 550, 551.

ketjil, zie caytchill.

kheniraam, titel van een inheemsch ambtenaar op Golkonda: 446, 447.

kimelaha, dikwijls geschreven quimelaha, Moluksche titel, in den tijd der Compagnie vertaald door stadhouder: $185,230,313$, 475.

kitchilly, zie caytchill.

koetika, Maleisch, tijd of tijdrekening: $\mathbf{4 4 5}$.

korkorre, zie cora-cora.

kromakan, Siameesche titel, eigenlijk van een rechter, maar ook gebruikt voor andere ambtenaren: 24, 331, 332, 393, 411, 412. kwarto-diensten, heerendiensten op Ambon: 382-385.

L.

lak, een hoeveelheid van 100.000 , meestal gezegd van ropia's: 145, 257-259, 316.

lascorijn, inheemsch soldaat: $\mathbf{1 4 8}$, $351,352$.

legger, 10. een watervat voor schepen van circa 400 L. inhoud: 43.

2o. het Hollandsche woord voor Portugeesch feitor, factor of resident: 229 .

legia, zijde van 2de kwaliteit: 5 . lorrendraaiers, smokkelaars, mo-nopoliebrekers: 13.

M.

maas, munt ter waarde van $1 / 10$ tael: 525.

maggain, provincie: 206.

Maggrebbers, verouderde naam voor Arabieren: 145.

mahmoedi, Perzische munt ter waarde van $1 / 100$ toman of ruim 40 cent: 457, 504 .

mamoela, op tal van wijzen verhaspeld, als mamnoea, mamnoeda, momnola etca, een speciaal in Bengalen gebruikt woord ter aanduiding van onwettige lasten, door de inheemsche ambtenaren aan de Compagnie en andere vreemde kooplieden opgelegd, en veelal vertaald door ,geltknevelarye". Zie ook Hobson-Jobson in voce mamool: 294, 297, 298, 300.

man of men, gewichtseenheid in Perzië, waarvan twee soorten bestonden, namelijk de man-ishah, \pm 6 K.G. en de man- $i$ tabriz, \pm 3 K.G. De min-i-shah was verdeeld in 1280 muskal: 210, 212, 451, 452, 462, 463, 496-498, 550, 552. 
manigar, titel voor een dorpshoofd aan de kust van Madura. Zie Hobson-Jobson in voce monigar: 378-380.

mansjour, inheemsch koopvaardijscheepje: 149.

mantri, algemeen verbreide titel. oorspronkelijk met de beteekenis minister, later ook voor lagere ambtenaren. Men leest herhaaldelijk ,mantries ofte regenten"; $270,273,323,325$, 326.

manuaar, pachter van een district: 567.

manzil, zie munzil.

marcal, rijstmaat, bevattende circa 20 pond rijst en verdeeld in 12 seer: 141.

mardijker, vrije Christen-inlander: 63, 71, 218.

matikael of matscael, zie muskal. meir-samaan, van mir, chef of

hoofd, en sāmān, goed, meubelen, bezittingen; titel voor het hoofd der garde-robe en sieraadkamers van den Grootmogol. WILSON vertaalt het door head-steward: 516 .

mendewies, Mahratti māndavi, douanekantoor, entrepot; in den tekst hiervóór vertaald door waag: 430.

menon of menavon, Malabaarsch, schrijver of klerk: 348.

mercanci, Portugeesch marcancia, koophandel: 295.

mocquaas, visschers op Malabaar: 363, 364.

modseddie, ambtenaar der kanselarij in het rijk van den Grootmogol: 8, 115, 294, 296, 298, 304, 327, 518.

moelawissael, tollen of ,weggelden": $\mathbf{4 1 6 .}$

moeterykoery, zekere gerechtigheid, te betalen op Koromandel: 252.

moetsilka, schriftelijk vastgestel- de verplichting, verbandschrift: 222, 223-225.

molla, geleerd man, kenner van den koran: 23, 263.

Moltaenders, naam voor Hindoesche kooplieden in Perzië: 110. momnola, zie mamoela.

Moor, Mohamedaan: 22, 179, 216, 256 etc $^{\mathrm{a}}$.

moradores, Portugeesch, ingezetenen: 202.

motteseddie, zie modseddie.

muharram, naam voor de 1e maand van het Mohamedaansche jaar, ook gebruikt als epitheton bij andere maandnamen, met de beteekenis: de verhevene; b.v. Schâban il Muharram: $\mathbf{4 3 5}$.

munzil, rustplaats voor karavanen: 105.

murajeb, epitheton bij Islamitische maandnamen, met de beteekenis het heilige jaar: 180 .

muskal, Perzische gewichtseenheid, onderdeel van de man-ishah; zie aldaar: 210, 212, 462, 463, 496-498, 550, 552.

mustaffi, Perzisch mustofi, belas-tinggaarder, hoofd der financiën: 153, 178, 189.

mustaffi-chassa, Perzisch mustofie-chazineh, kanselier van de schatkist; ,,superintendent van 's conings reeken- en financiekamers"; 7, 153, 493.

\section{N.}

nabab, gouverneur of onderkoning: 205, 207, 252, 276, 293, 408, 409, 446, 518.

nachoda of anachoda, titel voor een inheemsch schipper. Op enkele plaatsen, o.a. Sumatra's Westkust, ook titel voor een regent: 396.

naeyp, zie naib.

nagri, nagaree, het klassieke Sanskrit-alphabet: 295. 
naib, doubletvorm van nabab: 276, 293.

naik, vorstentitel aan de kust van Madura; ,vryheer of grave”: $377,378$.

nairos, leden van de militaire kaste op Malabar, ,ridders": $260,344,346-349,353,489$, 490, 510, 511.

nambeddy, Malabaarsche vorstentitel: 344, 489, 491, 509, 511.

nambiaar: Malabaarsche titel voor een Brahmaan: 515.

namboery: eveneens Malabaarsche titel voor een Brahmaan; waarschijnlijk identiek met het voorgaande woord: 354, 512.

nazir, inspecteur, ,opperste van 's conings cancelary": 493.

neli of nely, rijst in den bolster, padi: 141, 489, 506.

neyk, zie naik.

ngabehi, titel voor hooge Javaansche ambtenaren: 279, 282, 290, 323.

ngoffamanjirah, districtshoofd in de Molukken: 220, 313, 475.

nisaan, ,princelijck bevelschrift": 297, 299-301, 388 etc $^{\mathrm{a}}$.

\section{0.}

ockoen, Siameesche ambtenaarstitel: 393.

oekoeng, zie hoekoem.

oemboel, inheemsch bestuursambtenaar in de Preanger: 282.

ola, gedroogd palmblad, gebruikt 10. voor dakbedekking en 20 . als schrijfpapier. Door het onder 2 genoemde gebruik kreeg het woord ook de beteekenis van schriftelijke verklaring, privilege etc ${ }^{a}$ : 147, 259, 261, 333, 345, 349, 378, 380, 566 .

oluang, Siameesche beleefdheidstitel, ook wel geschreven luang: 69, 393, 411, 412.

oluang souraceen, Siameesche be- titeling van het Nederlandsche opperhoofd aldaar: 229, 274, 275, 321, 322, 331, 332, 393. ombol, zie oemboel.

omeun, Siameesche ambtenaarstitel: 393.

omrah, titel voor hooge hofambtenaren in Mohamedaansche staten: 221.

opra, Siameesche adellijke titel: 24, 69, 331, 332, 393, 411.

orangkaja, titel voor dorpshoofd in de Maleische landen: 37, 71, 136, 143, 445 etc $^{\mathrm{a}}$.

orangkaja-balay, leider van een negri: $71,80,83,265$. Zie ook op balai.

orangkaja-soudagare, „opsiender der negotie": 72.

orembaai, soort prauw: 168.

ottena, Japansch otona, wijkmeester: $\mathbf{5 6 4 .}$

oya, Siameesche titel, prins: 24, 331, 414.

oya berkelang, titel van den rijksbestuurder in Siam, de tusschenpersoon tusschen den koning en de vreemdelingen: 24, 25, 68, 69, 273, 274, 331, 393.

\section{P.}

pagalaran, een deel van den kraton, waar de Soenan bijeenkomsten samenroept, ,generale vergaderplaats": 323 .

pagode, gouden munt ter waarde van $f \quad 6$ en verdeeld in 12 fanums; op enkele plaatsen had men ook zilveren pagoden: 58 , $61,64,141,170,171,173,174$ etc $^{\mathrm{n}}$.

paligaar, leenvorst. Zie HobsonJobson in voce poligar: 377.

paljetter, titel van een invloedrijk prins op Cochin: 355 .

pallenquien, palankijn of draagstoel: 57.

pandaram, Hindoesch priester uit 
een lagere kaste dan die der Brahmanen: 141, 142.

pandidaar, regent of pachter: 55, 56.

pandit of pandito, geleerde, kenner der Sanskrit-wetenschap: 140.

panglima, Maleische titel voor een stadhouder of rijksbestuurder, ook in de copulatie panglima-radja: 135, 136, 143, 238, 239, 390, 392, 480.

panikaal, Malabaarsche vorstentitel: 506, 507.

pantel of panteloe, Brahmaansch hoogwaardigheidsbekleeder: 140, 252.

pardao, Portugeesche zilveren munt ter waarde van 300 reis: 141, 202, 204, 251, 252.

parra, 10. een rijstmaat van $1 / \mathbf{1 4}$ candil of circa 35 pond, maar meest gerekend op 40 pond. 2 o. een stuk land dat zoodanige hoeveelheid rijst oplevert: $\mathbf{5 1 4}$. parwanna, bevelschrift, „ordres der duwaans": passim.

pattamar, looper, briefdrager: 232.

pees, Portugeesch peça, stuks: 415.

peesdas, plaatsvervanger, assistent, Perzisch pēsh-dast. Zie ook Hobson-Jobson p. 816: 262. peon, Portugeesch peano, van pé, voet; bode of soldaat te voet: 57, 59, 328, 330.

perganna, district: 302, 398. pette, Hindostani pettah, dorp, voorstad, marktplaats: 147.

peykaar, inheemsch opkooper voor de Compagnie; ,voorkoper”: 303.

pia, Siameesche adelstitel: 24, 69, 332.

pikoel, draaglast van circa $621 / 2$ K.G.: 136.

pion, zie peon.

poele, zie pulle. pongel, pongloe of pounglou, schrijfwijzen voor panghoeloe, priester of regent: $28,29,32$, $34,37,48,50,71-77,79,81$, $86,136,143$ etc $^{\mathrm{a}}$.

praktijk, list: 178.

pulle, epitheton voor leden van de kaste der Sudra's, als suffix achter den naam geplaatst: 147, 329, 330, 364.

\section{Q.}

quimelaha, zie kimelaha.

\section{R.}

racam, zie rakam.

rachdaar, zie rahdar.

raderyen, zie rahdari.

radix-Chinae, gedroogd wortel, als medicijn gebruikt: 212,463 , 498, 552.

ragiador, regent: 133,, 175, 177, 349.

rahdar, inner der tolgelden; éénmaal hiervoor vertaald door leenman: 297, 299, 304.

rahdari, tol- of weggelden: 257, 276, 294, 297, 298, 300, 301, $305,316,327$ etc $^{\mathrm{a}}$.

rakam, een handschrift, een schriftelijk bevel. Zie WILSON in voce. Het wordt meestal gebruikt voor een geschrift van een vorst, wat mogelijk de oorzaak is dat de Portugeezen en de na hen in Indië gekomen Europeanen dikwijls regam schrijven. Zie beneden op dat woord en Valentijn, V, I, Persiën, blz. 271, „Regam of koninklyken brief": 189, 212, 465-469.

rakit of raket, verankerd bamboevlot, waarop een huis is gebouwd: 540, 541.

rasiename, verbastering van Hindostani raddnâma, herroeping; een stuk, waarbij een ouder document wordt ingetrokken: $\mathbf{5 1 9}$. 
rawanna, Hindostani rowannah, pas: 519.

regam, koninklijk schrijven: 189, 212. Zie verder op rakam.

rokta of roocka, aanteekening: 116.

rompaarden, rampaarden, rolpaarden, ropaarden $\mathrm{etc}^{\mathrm{a}}$, lage korte scheepsaffuiten: 167.

ropia, zilveren munt ter waarde van 28 Hollandsche stuivers en verdeeld in 16 anna's: 22, 256 $-259,316,402,404$ etc $^{\mathrm{n}}$.

\section{S.}

sabandaar, zie sjahbandar.

sahib: heer: 493.

sahib-fousie, ,eerste acteschryver, taxeerder en visitateur des conings" van Perzië: 493.

salimoet, naam voor zekere tolrechten aan de Westkust van Sumatra: 136.

sampan, inheemsch zeilvaartuig: 218.

sayer, naam voor de gezamenlijke tollen en rechten in Bengalen, met uitzondering van de z.g. landrechten: 327.

sekoet, verzamelnaam voor ,allerley soort van land- en andere thollen, exepto die op den vervoer ter zee werden betaalt": $420,425,430,431,436$.

sembah of sembahjang, begroeting, eerbewijzing, eerbiedige huldebetuiging: 73, 241, 393.

sengadji, regent of districtshoofd in de Molukken: 313.

serbethuizen, huizen waar de provisiën, kleederen en sieraden van de hofhouding van den sjah van Perzië worden opgeslagen, ,gebruykhuysen": 211, 497, 551 .

ser-charwān, een pakje zijde, dat op elke charwary of last van D1. 93. die stof werd gelegd en als geschenk of toegift gold: 453.

serlasker, oorspronkelijk hoofd van het leger, later titel voor den onderkoning van Orissa: 119.

siauclang, zie chao-klang.

siemadaar, zie jemadar.

sjahbandar, havenmeester, meestal hoofd van den handel en belast met het toezicht op de vreemdelingen: $6,153,178$, 448, 524, 532, 533, 539, 569.

sjahboutria, koninklijke waag te Hoegli: 295.

sjaer, een soort visch in Tanjore: $120,121$.

sjonkan, in- en uitvoerrechten: 204, 252.

sjoukidaar en sioukidaer, zic chokidar.

soeba, zie souba.

somba en sombayen, zie sembah. songsong, riviermond: $\mathbf{5 4 1}$.

souba, provincie; de gouverneur van zoo'n provincie heet soubadar, maar wordt ook wel kortweg souba genoemd, wat men vrijwel steeds vertaald vindt door vice-roy. Zijn ambtsgebied duidt men dan aan met het woord soubaschap: 23, 57, $115,262,263,293,302,305$, 327, 387, 401, 427, 568. soussang, zie songsong.

\section{T.}

tabijn, volgeling, dienaar ,substituyt": $499,552$.

tackied, takid, bevelschrift: 206. tadsyker, Perzisch tadjik, stadsbewoner: 110.

taël of thail, 10. gewichtseenheid van $1 / 16$ catti of $371 / 2$ gram; 20 . munt van zoodanige hoeveelheid goud of zilver, en verdeeld in 10 mazen: $442,473,563$. 
tallika, factuur of inventarislijst, ,specifieke opgifte": 297, 300, 302.

teuver, vorstentitel aan de kust van Madura, ,vryheer”: 146150, 328-330, 333.

thail, zie taël.

thony, klein open vaartuig, door de paarlvisschers gebruikt: 148, 149 .

tjauwclangh, zie chao-klang.

toeman, zie toman.

toemenggoeng, hooge Javaansche titel, thans praedicaat voor regenten van adellijke afstamming, bij de Compagnie vaak gebruikt voor fiskaal of baljuw: $253,270,272,277,284,288$ etc". toepas, naam voor een vrije Christen-inlander in Voor-Indië: 63, 351, 352, 364.

toktokken, het in stukken hakken van een slaaf in plaats van een moordenaar: 163 .

toman of thoman, Perzische rekenmunt ter waarde van f 40 á f 42,50, verdeeld in 100 mahmoedi en in 10000 dinar: $5-7$, $116-118,127,152,153,210$. 211, 213 etc $^{\mathrm{a}}$.

tomilallang, Boegineesche titel: 376.

tommagon, zie toemenggoeng. tra, Siameesch, paspoort: 394. tsjauklang, zie chao-klang. tulmulk: rijksvertrouwde: 8 . turki, Perzisch, nomaden, het tegengestelde van tadjik: 110.

\section{V.}

visiadoor, Portugeesch vigiador, oorspronkelijk waker, hoofd der politie: 141, 142.

\section{W.}

wacar, een last zijde in Perzië, ter zwaarte van 216 K.G., dus evenveel als een carga: 452, 455, $460,461$.

wackenawies, Hindostani wakanivis, hoog ambtenaar aan het hof van den Grootmogol, majordomus. Hotz, Cunaeus, blz. 383 geeft den Perzischen vorm waki'ah neviss, plaatsvervanger van den grootvizier: 23.

wakil, Arabisch, plaatsvervanger of vertegenwoordiger; in VoorIndië dikwijls geschreven hockiel: 7, 72, 226, 276, 292, 388, 401, 427, 446.

wellinametti, zekere ongeoorloofde tollen in Perzië: 213.

\section{Z.}

zoy, Atjehsche inhoudsmaat van circa 40 liter: 43. 